\title{
Design and Analysis of Collapsible Scissor Bridge
}

\author{
Mohamad Nabil Aklif Biro", and Noor Zafirah Abu Bakar \\ Department of Mechanical Engineering, School of Engineering, Taylor's University, Malaysia
}

\begin{abstract}
Collapsible scissor bridge is a portable bridge that can be deployed during emergency state to access remote areas that are affected by disaster such as flood. The objective of this research is to design a collapsible scissor bridge which is able to be transported by a $4 \times 4$ vehicle and to be deployed to connect remote areas. The design is done by using Solidworks and numerical analysis for structural strength is conducted via ANSYS. The research starts with parameters setting and modelling. Finite element analysis is conducted to analyze the strength by determining the safety factor of the bridge. Kutzbach equation is also analyzed to ensure that the mechanism is able to meet the targeted degree of motion. There are five major components of the scissor structure; pin, deck, cross shaft and deck shaft. The structure is controlled by hydraulic pump driven by a motor for the motions. Material used in simulation is A36 structural steel due to limited library in ANSYS. However, the proposed material is Fiber Reinforced Polymer (FRP) composites as they have a high strength to weight ratio. FRP also tends to be corrosion resistance and this characteristic is useful in flooded area.
\end{abstract}

\section{Introduction}

Flood is one of the common disasters in tropical countries. Malaysia East Coasts Environmental Research Institute of University Sultan Zainal Abiden (USZA) claimed that $29,800 \mathrm{~km}^{2}$ of vulnerable area to this disaster sourcing from a few numbers of river basins in peninsular Malaysia and almost 4.82 million residents are at risk especially during monsoon seasons [1]. As a result, certain areas that are heavily affected have high potential to loss access to the outside world during flood.

According to the Annual Report 2014 by Malaysia Rescue Team or BOMBA, it is suggested that they revise their existing disaster Standard Operating Procedure [2]. It is also mentioned in the report that they would have to increase logistics capabilities such as adding more equipment and have more boats and trucks to standby for this disastrous phenomenon. However, this suggestion might not be the best solution to this problem in accessing remote areas. In conjunction to that, Research team at Hiroshima University had successfully developed and tested a folding bridge which is inspired by Japanese traditional origami [3]. The bridge is intended to be deployed during chaotic situations. Nevertheless,

* Corresponding author: nabil.aklif@yahoo.com 
the structure made is heavy and complex and took about one hour to assemble the components [4].

Adapting from the Nuremberg scissor concept, a collapsible bridge is one the solutions to provide passage for evacuation or bring in supplies. Nuremberg scissors is a planar mechanism consisting several links and pins forming a scissor-like structure which has the ability to collapse and expand with a given ratio. This bridge is able to operate with a minimum amount of force to expand and retract. With a force in the horizontal direction of the link, it provides a collateral force to the other link and expands the bridge. The motion of the structure must satisfy Kutzbach equation or criterion by determining the degree of freedom of the mechanism. This is done by obtaining the number of links and number and types of joints that is included in the system as a whole [5].

The project objectives are to design a collapsible light weight scissor-like bridge, to simulate its motion and to assess its structural strength. The mechanism of the bridge must satisfy Kutzbach equation which produces two degree of motion with specific number of links and joints.

The design scope does not consider the ground elevation or ground damping during flood. Soil damping naturally occur to areas where rivers are near and also during heavy rainfall that causes flood. Upon operation of the bridge at the area, ground condition might cause the bridge to operate at a certain angle which is not specifically analyzed in this project. Regarding the material, the proposed material for future development is FRP. Due to limited library function in ANSYS, A36 structural steel is chosen for numerical simulation.

\section{Research Methodology}

\subsection{Design Parameters}

The bridge is designed to fit a typical $4 \times 4$ pick-up truck which has average dimensions of width, $W_{v}: 1860 \mathrm{~mm}$ and height, $H_{v}: 1815 \mathrm{~mm}$. Thus, the outer dimensions of the structure are set to be slightly bigger with width, $W_{s}: 2200 \mathrm{~mm}$ and height, $H_{s}: 2000 \mathrm{~mm}$. The expansion ratio is adapted from an industrial scissor lift which has a common ratio of 1:5. Thus, the minimum length for the expansion mode of the bridge is $14000 \mathrm{~mm}$. The condition of expansion and retraction modes are shown in Fig. 1.

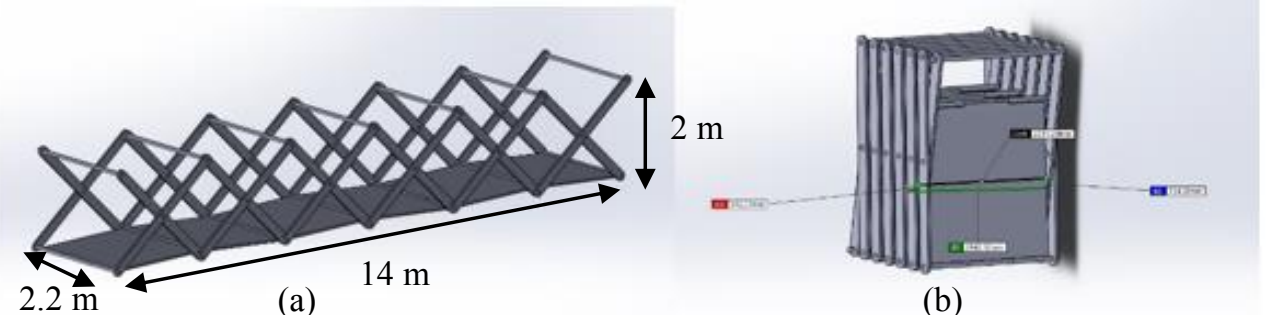

Fig. 1. Scissor structure (a) Expansion mode and (b) Retraction mode

The structure is designed to withstand maximum allowable load which are the summation of the total weight of all bridge components and the gross weight of the vehicle which is $1950 \mathrm{~kg}$. The gross weight of the vehicle consists of the weight of the vehicle plus the passengers and cargo weight.

\subsection{Components Design}

The components of the bridge are categorized into structural components and auxiliary components. Fig. 2 shows the components as a complete structure which consists of six sets 
of scissor link cross, auxiliary components (pump and hydraulic cylinder) and structural support to mount the auxiliary components and the first set of scissor link cross.

\subsubsection{Structural components}

The set of scissor link cross consists of four links, a deck, a cross shaft, a deck shaft and a pin as shown in Fig. 3. There are 56 parts in total for the structure. SolidWorks is used to create the design and Motion Study function is used to visualize the motion of the structure.

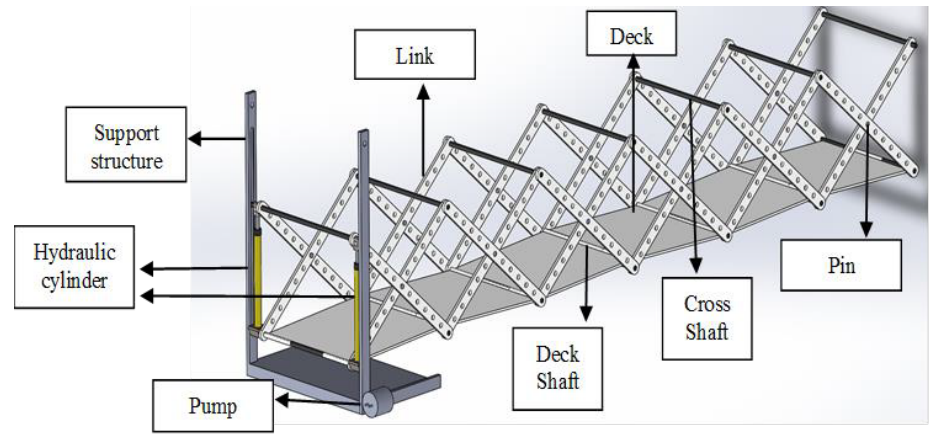

Fig. 2. Complete model of the bridge

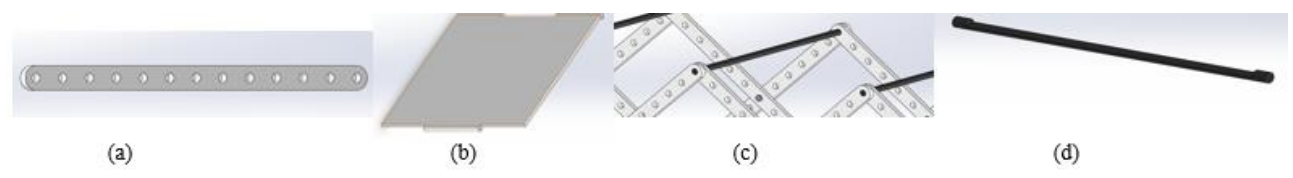

Fig. 3. Structural components : (a) Link, (b) deck, (c) cross shaft, and (d) deck shaft

The dimension of the link is selected according to the optimum strength and weight of the link. These links hold up $40 \%$ of the total weight of the bridge and are considered as a major component to the structure. The deck serves as the main unit to allow traffic on the scissor bridge to pass through. The design of the deck is made with the interlocking method. With multiple arrangement of the deck, it can be combined to expand the length. Another feature of using this interlocking design is it allows the folding mechanism for the bridge to retract to the folded state. The cross shaft holds the links together and provides angular movement to the links. This cross shaft is designed in the shape of a normal cylindrical rod. Deck shaft serves similar purpose to the cross shaft except that in the middle part it has a flat surface to allow the deck to rest on it when the structure is opened at horizontal state. The pin serves a simple purpose to the structure which is to hold the links in position and to provide angular movement or rotation to the links. In other words, the pin acts similar to a bearing. However, in the real scale scissor bridge, this pin must accompanied with sets of bearing as it is an integrated component with the links.

\subsubsection{Auxiliary components}

The auxiliary components consisted of a hydraulic cylinder, single-acting type and a pump. Single-acting cylinder as shown in Fig. 4 is a type of cylinder that is pressurized at only one end and the other end is vented or exposed to the atmosphere [6]. The motion of the scissor bridge is governed by the principle of work and energy equation as shown in Eq.(1).

$$
\begin{array}{r}
T_{1}+\sum U_{1-2}=T_{2} \\
T_{i}=1 / 2 m v_{i}^{2}
\end{array}
$$




$$
\sum U_{1-2}=F \Delta d+m g h
$$

$T_{1}$ represents the kinetic energy at initial state and $T_{2}$ is the kinetic energy at final state as shown in Eq.(2). Velocity $v_{l}$ at initial state is always equal to zero and velocity $v_{2}$ at final state is a dependent variable. $\sum U_{1-2}$ consists of the work done by the piston inside the hydraulic cylinder and work done by gravitational force as shown in Eq.(3). The hydraulic cylinder force $F$ is caused by hydraulic pressure and $\Delta d$ is the piston displacement. The variable $m$ is the total mass of the structure and $g$ is the gravitational acceleration which is assume to be $9.81 \mathrm{~m} / \mathrm{s}^{2}$ and both are constant. The vertical distance travelled by the bridge during expansion and retraction is given by $h$ and can be found during the motion simulation. By solving Eq.(1-3), the hydraulic cylinder force $F$ can be determined. By applying Eq.(4), the power of the pump $P$ required to move the structure can be calculated. The pressure inside the cylinder $p$ can also be determined by using Eq.(5) where $A$ is the cylinder's constant cross sectional area.

$$
\begin{aligned}
& P=F v_{2} \\
& p=F / A
\end{aligned}
$$
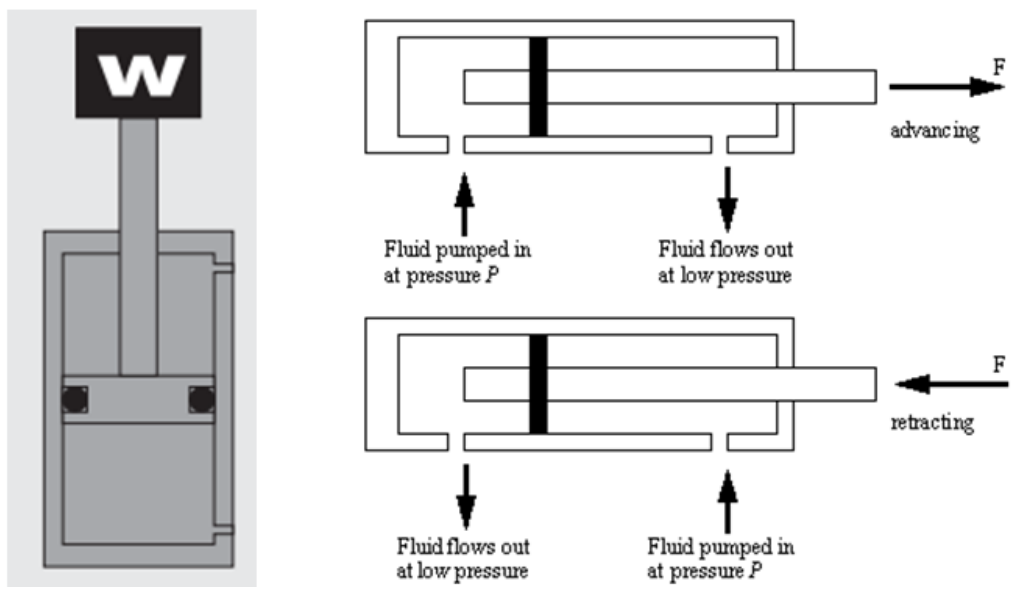

Fig.4. Single-acting cylinder [6]

\subsection{Structural Analysis}

\subsubsection{Stress analysis by ANSYS Workbench (Static Structural)}

Stress analysis is simulated by utilizing ANSYS Workbench with the feature of Static Structural. In this analysis, the main objective is to validate whether the structure assembly is able to withstand the targeted load by showing a major deformation. In ANSYS Workbench, the simulation is done with a few fixed parameters. Meshing is done by using coarse span angle center for a faster simulation and meshing processes. Element size is set to default which the software decides the best element size for the model. The nodes obtained from this meshing is 302927 and generated 131688 elements, which shows sufficient numbers of element to proceed the analysis.

Safety factor is determined from the numerical result by using Eq.(6). 


\subsection{Motion analysis}

\subsubsection{SolidWorks Motion Study}

Motion Study is done by Solidworks. In this function, force is applied to the piston to provide movement to the structure and the animation of the structure is successfully developed. The motion is vice versa as the force to the piston is directed to the opposite side.

\subsubsection{Kutzbach equation (Degree of Freedom)}

It is important to determine the degree of freedom of a design or mechanism to ensure the movability. This is done by determining the number of links and joints included in the system. In this case, taking one set of the scissor structure should suffice to prove that the degree of freedom is two; in horizontal and vertical motion of the structure. Kutzbach equation is shown in Eq.(7).

$$
n=3(l-1)-2 j-h
$$

Where, $n=$ number of degree of freedom, $l=$ total number of links, $j=$ total number of primary joints and $h=$ total number of higher-order joints.

\subsection{Material Selection}

As suggested by studies, Fibre Reinforced Polymer composites has some advantages when compared to conventional construction materials [7]. FRP is very strong as it dominates the high specific strength and stiffness. It also has a high strength to weight ratio which means the future scissor bridge can be lighter than expected if FRP is chosen to be its main material [8]. Other than that, it is a corrosion resistance material and this could reduce the maintenance cost of the bridge [9]. As claimed by studies, deck with FRP are usually multilayer which is also known popularly as sandwiches. The weight of this FRP is approximately lower by $20 \%$ compared to the conventional concrete slab [7]. However, this section is not covered in detail as it is not in the scope of the project and this preliminary study should suffice for the project up to this stage. Throughout this project, A36 structural steel is selected for simulation due to the limitations experienced as ANSYS library is not able to support mixture of material properties.

\section{Results and Discussion}

\subsection{Dimension Table}

Several design iterations are needed to ensure that the structure is at its optimum strength and meet the scope of the project. Table 1 below shows the summary of the dimensions of the components for the scissor structure.

Table 1. Components list and design specifications

\begin{tabular}{|c|c|c|c|}
\hline Component & Function & Dimension & Material \\
\hline Link & - Structural support & $\begin{array}{l}\text { - } \quad \text { Length: } 3312 \mathrm{~mm} \\
\text { - } \quad \text { Hole diameter: } 80 \mathrm{~mm}\end{array}$ & $\begin{array}{l}\text { Steel } \\
\text { (A36) }\end{array}$ \\
\hline Cross Shaft & $\begin{array}{ll}\text { - } & \text { Structural support } \\
\text { - } & \text { Provide angular movement }\end{array}$ & $\begin{array}{l}\text { - } \text { Length: } 2440 \mathrm{~mm} \\
\text { - } \\
\text { Diameter: } 78 \mathrm{~mm}\end{array}$ & $\begin{array}{l}\text { Steel } \\
\text { (A36) }\end{array}$ \\
\hline
\end{tabular}




\begin{tabular}{|c|c|c|c|}
\hline Deck & $\begin{array}{l}\text { Main feature as platform for } \\
\text { usage }\end{array}$ & $\begin{array}{ll}\text { - } & \text { Length: } 2340 \mathrm{~mm} \\
\text { - } & \text { Width: } 2200 \mathrm{~mm} \\
\text { - } & \text { Hole diameter: } 78 \mathrm{~mm}\end{array}$ & $\begin{array}{l}\text { Steel } \\
\text { (A36) }\end{array}$ \\
\hline Pin & $\begin{array}{l}\text { - Minor structural support } \\
\text { - } \quad \text { Provide angular movement }\end{array}$ & $\begin{array}{l}\text { - Length: } 120 \mathrm{~mm} \\
\text { - } \quad \text { Diameter: } 78 \mathrm{~mm}\end{array}$ & $\begin{array}{l}\text { Steel } \\
(\mathrm{A} 36)\end{array}$ \\
\hline Deck Shaft & $\begin{array}{l}\text { - } \\
\text { - } \\
\text { - } \\
\text { - }\end{array}$ & $\begin{array}{l}\text { - Length: } 2440 \mathrm{~mm} \\
\text { - } \quad \text { Diameter: } 78 \mathrm{~mm}\end{array}$ & $\begin{array}{l}\text { Steel } \\
\text { (A36) }\end{array}$ \\
\hline
\end{tabular}

\subsection{Stress analysis}

Fig. 5 shows the forces applied to the structure which in total of $210070 \mathrm{~N}$. These forces are assumed to be the forces that will be exerted by the 2.6 unit of $4 \times 4$ pick-up truck during its operation. In this simulation, both of the end of the structure is set to be the fixed support.

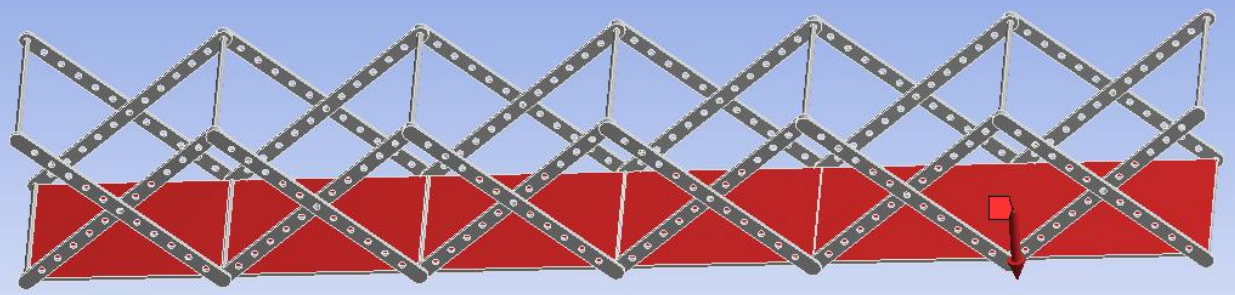

Fig.5. Uniform load applied to the structure

Fig. 6 shows the total deformation of the scissor structure after load of $210070 \mathrm{~N}$ is applied to the middle section (red contour). The maximum deformation is $15.741 \mathrm{~mm}$. This shows that when the targeted load which is the typical $4 \times 4$ pick-up truck passes by, the structure is able to withstand the force exerted. Take note that the load applied is the gross weight of the truck which means it is inclusive of the weight of the vehicle with its cargo on the back side. With remarks from a study made by a group of researchers, the similar design of structure passed the experimental test to carry two set of loads; $13.6 \mathrm{kN}$ and 10 $\mathrm{kN}$ and also it is claimed that the analytical value had less than $10 \%$ of error [10].

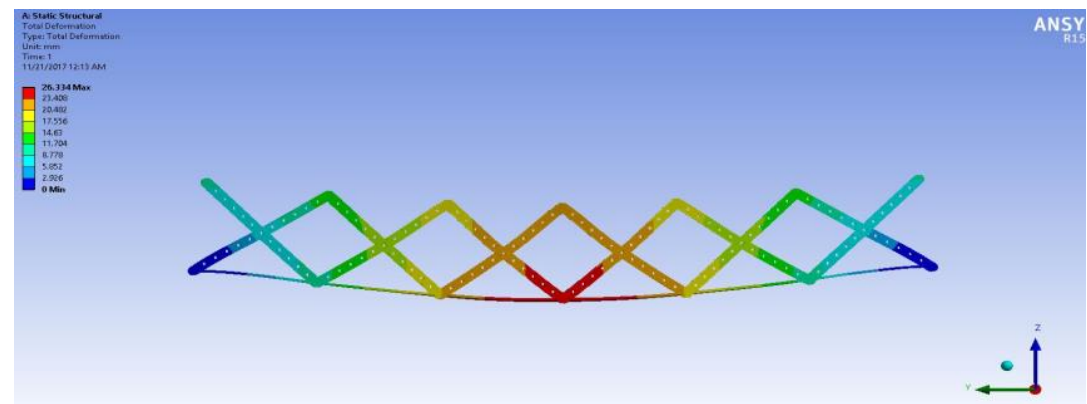

Fig.6. Total Deformation contour of scissor structure 
There are two type of stresses that can be obtained from ANSYS Static Structural analysis, Von-Mises stress (equivalent stress) and also maximum principle stress. Based on Fig. 7, the highest value of maximum principle stress is $138.64 \mathrm{MPa}$ and from Fig. 8 the equivalent stress has the value of $149.48 \mathrm{MPa}$ at maximum.

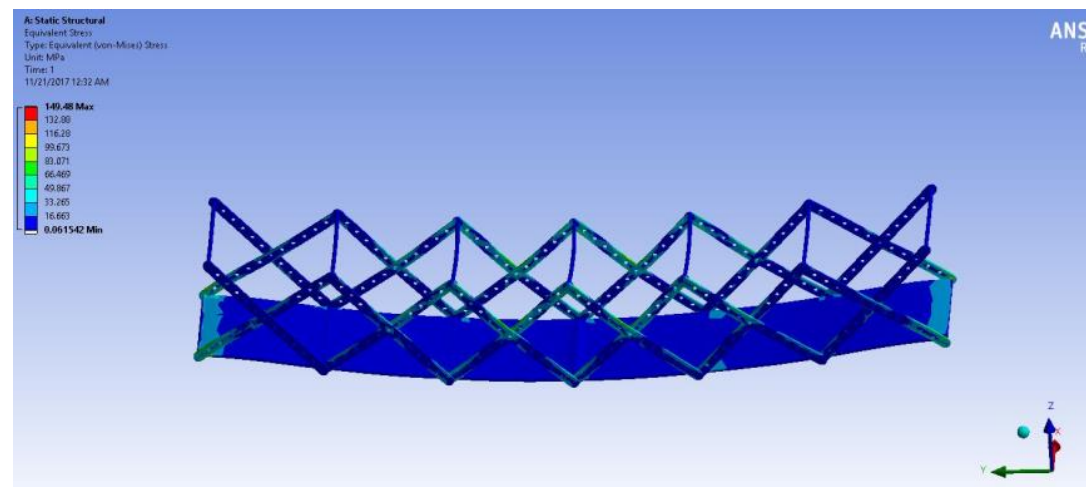

Fig.7. Maximum Principle Stress on structure

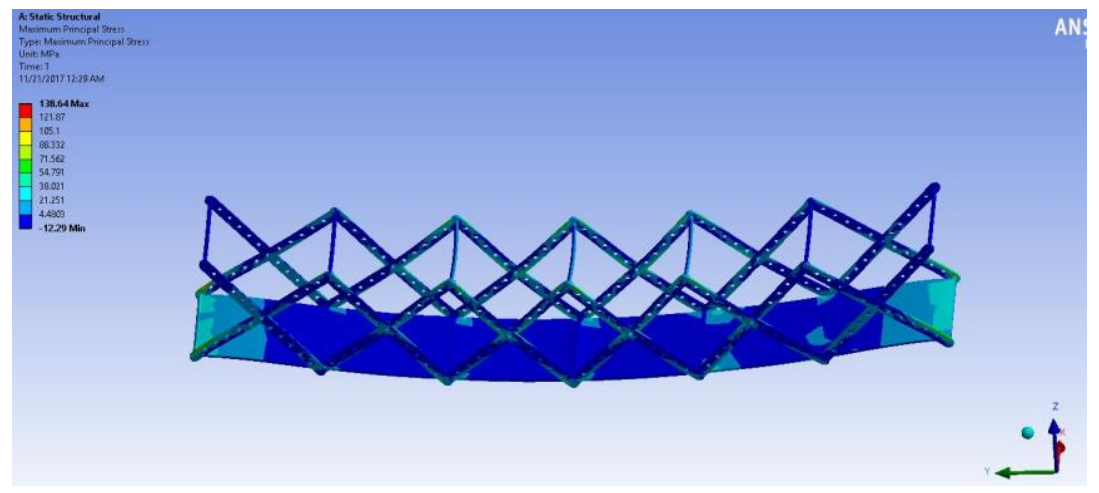

Fig.8. Von-Mises stress

These values are used to obtain the safety factor of the scissor bridge by using the Eq.(6). In this case, yield stress is provided by the properties of A36 structural steel which is $250 \mathrm{MPa}$. By using the value from maximum principle stress and equivalent stress (vonmises) which is $138.64 \mathrm{MPa}$ and $149.48 \mathrm{MPa}$ respectively, the factor of safety is obtained.

From maximum principle stress, the safety factor is 1.803 . From equivalent stress, the safety factor is 1.672 .

These values support that the structure is able to withstand the load of $210070 \mathrm{~N}$ and to clarify this value, the load value used is a summation of the total weight of the structure and the maximum load of 2.6 units of the trucks on the bridge by taking one length of the truck, $5277 \mathrm{~mm}$ and fitting as many truck as possible onto the $14000 \mathrm{~mm}$ scissor bridge.

However, this value changes when only one $4 \times 4$ truck is allowed to pass at one time. When this condition is used, the load applied will be only $19100 \mathrm{~N}$ and the maximum deflection is $13.451 \mathrm{~mm}$ with $118.47 \mathrm{MPa}$ of maximum principle stress and $127.73 \mathrm{MPa}$ of equivalent stress (von-mises). These values can be found in Fig. 9, Fig. 10 and Fig. 11. 


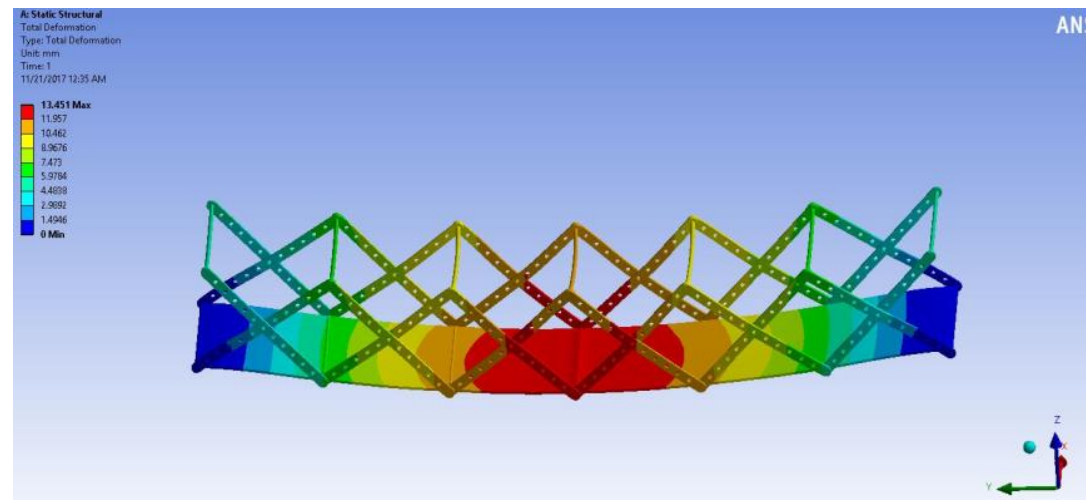

Fig.9. Total deflection for one truck loading

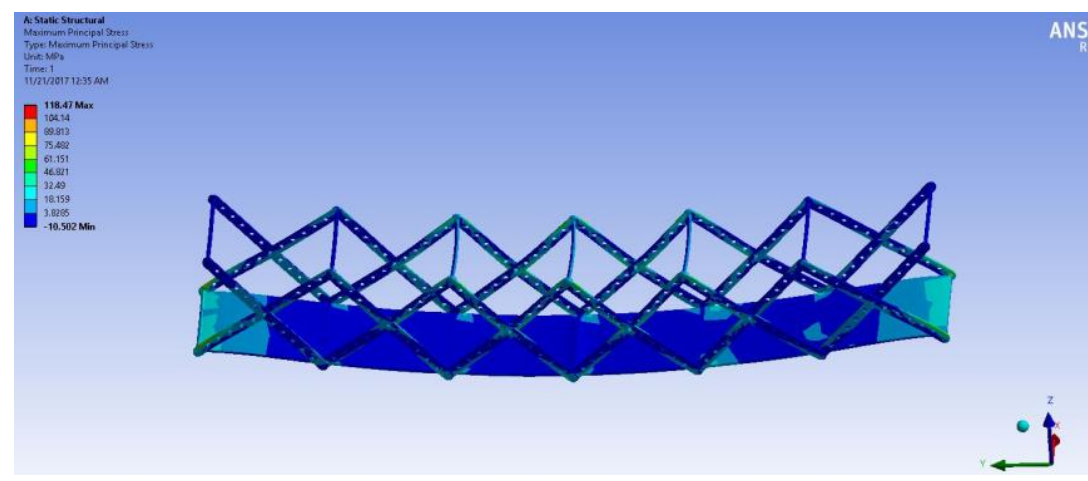

Fig.10. Maximum principle stress for one truck loading

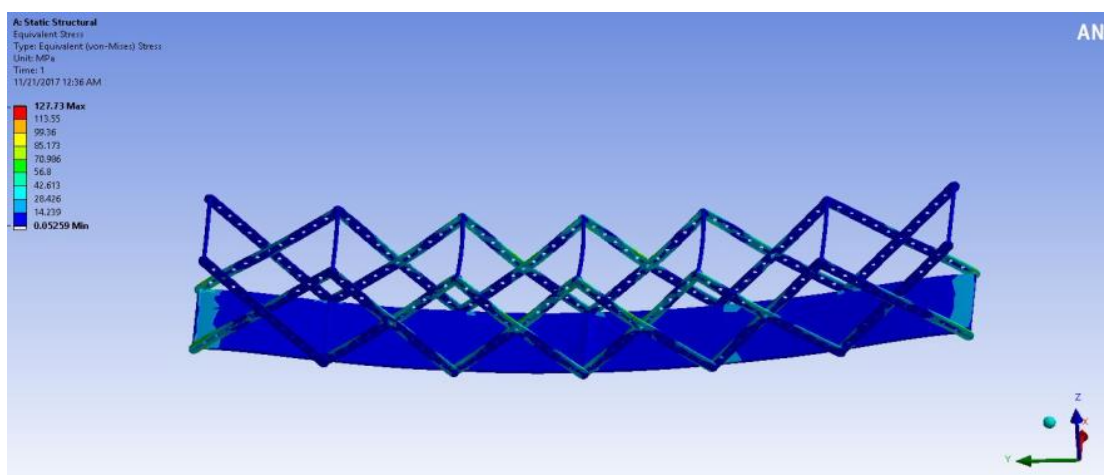

Fig.11. Von-mises stress for one truck loading

\subsection{Motion Analysis}

\subsubsection{Force Needed to Operate Scissor Bridge by Work-Energy Principle}

The force required for the structure to expand is governed by Eq.(1-3) with an input of velocity in kinetic energy equation.

Table 2 below shows the variation of velocity input and force required. From Table 2, the optimum velocity of the structure is $4.43 \mathrm{~m} / \mathrm{s}$ as it requires minimum amount of force to expand, which is $40.06184 \mathrm{~N}$ and force to retract is $324393.8 \mathrm{~N}$. Higher force is needed to 
retract because of the extra work needed to counter the gravitational force downwards as the piston needs to move upwards.

Table 2. Calculation summary for Varied Velocity

\begin{tabular}{|c|c|c|}
\hline $\begin{array}{c}\text { Velocity of Structure } \\
(\mathrm{m} / \mathrm{s})\end{array}$ & Force to expand $(\mathrm{N})$ & Force to retract $(\mathrm{kN})$ \\
\hline 4 & -29.5967 & 294.4308 \\
\hline 4.3 & -9.23875 & 315.0129 \\
\hline 4.43 & 0.040062 & 324.3938 \\
\hline 5 & 43.98626 & 368.8238 \\
\hline 6 & 133.921 & 459.7485 \\
\hline 7 & 240.2075 & 567.205 \\
\hline
\end{tabular}

Fixing the cross section area of the cylindrical hydraulic $A$ with design of the piston radius of $0.125 \mathrm{~m}$, the pressure inside is $P=6608.48 \mathrm{kPa}$ by applying Eq.(5). For the selection of motor specification by power, the force and the velocity are multiplied as shown in Eq.(4) and the values can be compared with readily available motor in the market.

\subsubsection{Kutzbach equation}

By extracting one set of the scissor structure, the number of links is $l=5$, the number of primary joints is $j=5$, and the number of higher-order joints is $h=0$. By applying Eq.(7), the number of motion or degree of freedom is $n=2$. Thus, it proved that the design mechanism is workable and able to produce two kind motions which are vertically and horizontally as shown in Fig. 12.

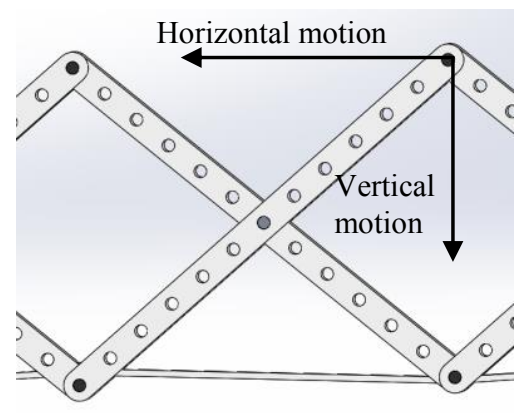

Fig.12 One set of scissor structure motions

\section{Conclusion and Recommendation}

This paper presents a thorough theoretical and numerical analysis of the scissor structure accompanied with the auxiliary components. Design of the structure are based on the literature reviews and cited studies from other research papers supported with structure analysis in results and discussion section. The structure able to satisfy Kutzbach equation and has satisfactory safety factor. Hence, the objectives of the project are also met Following from that, this project has numerical analysis on the collapsible bridge and also 
This paper also reveals the basic design of the collapsible scissor bridge by parts and each function of the parts are justified.

Moving forward, numerical analysis using FRP as main material should be further investigated to design the bridge to be more lightweight and portable. The fluid analysis on the structure caused by wind can also be a potential area to analyze to ensure that the structure design is more robust.

\section{References}

1. M.B. Gasim, M.E. Toriman, M.G. Abdullahi, FLOODS IN MALAYSIA Historical Reviews, Causes, Effects and Mitigations Approach, IJIR 2(4) 59-65 (2014).

2. JBPM, Annual Report 2014, Fire and Rescue Department of Malaysia (2014).

3. Y. Chikahiro, I. Ario, M. Nakazawa, S. Ono, J. Holnicki-Szulc, P. Pawlowski, C. Graczykowski, An experimental study on the design method of a real-sized Mobile Bridge for a moving vehicle, MRAS IV 13693 (2014).

4. N. Bronner, MB 4.0: The Future Of Bridge Technology. http://www.pitt.edu/ nbb8/eti.html. (Accessed 18-Nov-2017 2017).

5. R. Khurmi, J. Gupta, Theory of machines, Eurasia (1976).

6. M. Cylinder, Design Engineering Guide, Actuant Corp (2012).

7. P.B. Potyrala, Use of Fibre Reinforced Polymeromposites in Bridge Construction. State of the Art in Hybrid and All-composite Structures, Universitat Politècnica de Catalunya. Escola Tècnica Superior d'Enginyers de Camins, Canals i Ports de Barcelona. Departament d'Enginyeria de la Construcció (2011).

8. T.A. Hoffard, L.J. Malvar, Fiber-reinforced polymer composites in bridges: a state-ofthe-art report, Naval Facilities Engineering command Port Hueneme ca Engineering Service Center (2005).

9. T. Keller, Use of Fibre Reinforted Polvmers in Bridge Coni truc tion, (2003).

10. Y. Chikahiro, I. Ario, M. Nakazawa, S. Ono, J. Holnicki-Szulc, P. Pawlowski, C. Graczykowski, Structural Analysis and Experimental Study for realsized MB Travelable Vehicles, Proc. of the 8th European Nonlinear Dynamics Conference pp. 12. (2014) 